\title{
Study on Textural Quality of Extrudates Prepared from Different Blends of Sattu and Kodo
}

\author{
Devendra Kumar ${ }^{1 *}$, Mohan Singh $^{2}$, Shobha Rani $^{3}$ and Varsha Kumari ${ }^{4}$ \\ ${ }^{1} P F E, C A E$, DRPCAU, Pusa, India \\ ${ }^{2}$ Department of PHP\&FE, JNKVV (Jabalpur), India \\ ${ }^{3} K V K$, Jehanabad, India \\ ${ }^{4}$ S.M.S.(H.Sc.), KVK, Vaishali, India \\ *Corresponding author
}

\section{A B S T R A C T}

Keywords

Kodo, Extruder, Moisture, Sattu, Millet

Article Info

Accepted:

30 May 2020

Available Online:

10 June 2020
In the present study extrudates were prepared to identify the optimum machine parameters and prepare good quality ready to eat extruded snacks from a suitable blend of sattu and kodo. The crispness of extrudates decreases, with increase in blend ratio of sattu and screw speed and increases with increase in barrel temperature, and diehead temperature. The crispness of extrudates attained maximum and minimum count of 5.9 and 2.3. Hardness of extrudates increases with increase in blend ratio of sattu, whereas with increases in moisture content and increases very slowly with increase in die head temperature and screw speed. The maximum value of hardness of extrudates was found to be $19 \mathrm{~kg}$ whereas its minimum value was $1.5 \mathrm{~kg}$. The cutting strength of extrudates increases with increase in blend ratio of sattu increase in moisture content of feed and has very little effect in the increase in barrel temperature and die head temperature and screw speed. Cutting strength of extrudates achieved a maximum value of $10.58 \mathrm{~kg}$ and it had a minimum value of $0.7 \mathrm{~kg}$.

\section{Introduction}

Extrusion cooking has the potential to become one of the most promising frontier technologies suitable to prepare good quality engineered food products. Extrusion cooking can be defined as a cooking process consisting of forcing the food materials through a specially designed opening after prior treatment. It aims to produce a voluminous, expanded, crispy product. The concept of extrusion cooking has potential to become one of the most promising frontier technologies suitable to prepare good quality engineered food products. Extrusion cooking is an HTST process where starches are 
gelatinized, processed denatured and extrudates are texturally and histological restructured. HTST extrusion reduces the microbial contamination. It is popular because of reduced processing cost, higher production rate, versatility to produce wide variety of products and is effluent free.

Sachez et al., (2004), in an effort to producer low cost extrudates from whole sorghum kernel, utilized a simple adiabatic, friction extruder of relatively low cost to directly process whole sorghum kernels into whole grain snacks with acceptable texture and found that extrudates made from whole sorghum had a harder gritty texture than those made from decorticated materials. They also reported that grinding whole sorghum and removing fines did not improve product expansion during extrusion but altered the gritty pieces in the extrudates. The best products were obtained when whole sorghum (ground or un-ground) was extruded at 14\% moisture and the whole sorghum extrudates had larger bubbled with thick cell walls, which made extrudates more crunchy. Extrusion aims at producing a voluminous, expanded, crispy product resembling a baked product. There is no principal limitation in terms of the raw materials, which can be used for extrusion.

Anti-nutritive compounds can be reduced during extrusion to provide safer and more nutritious foods (Harper, 1981). Using extrusion cooking technology good blend ratios optimum machine and process parameters can be identified to fortify the kodo with sattu (mixture of roasted gram wheat and barley powder in the ratio of 80:10:10 for ready to eat extruded snacks

\section{Materials and Methods}

Sattu and kodo were procured from local market. After initial removal of foreign materials, all the mixture of sattu powder and kodo flour) were blended in predetermined proportions and mixed thoroughly in mixer and then they were fed to the Brabender single screw extruder at specific moisture content for making the extruded product at different predetermined set of operations.

The experiments were carried out to find out the effect of different levels of processing parameters namely moisture contents of feed $(8,10,12,14$ and $16 \%)$, blend ratios i.e. sattu : kodo (70:30, 60:40, 50:50, 40:60 and 30:70), the proportion of roasted gram, wheat, barley powder in a constant proportion i.e. 80:10:10. The machine parameters that were varied to get the appropriate temperature $(160,170$, 180,190 and $\left.200{ }^{\circ} \mathrm{C}\right)$ and screw speed (70, $90,110,130$ and $150 \mathrm{rpm}$ ) on textural properties namely hardness, crispness, and cutting strength of extrudates.

\section{Textural analysis}

Texture Analyzer model TA - XT2i (Plate 3.1) available at the department of Post Harvest Process and Food Engineering, CAE, Jabalpur is a highly scientific device was used determination of mechanical properties of extrudates i.e. parameters of texture such as hardness, crispness, sponginess, cutting strength, and crushing strength etc. with the help of different kinds of probes, Texture analyzer is totally a graphical user interface based tool which as soon as read the desired force.

\section{Results and Discussion}

\section{Textural properties}

\section{Crispness}

The multiple regression analysis for crispness of extrudates versus feed moisture content $\left(\mathrm{MC}_{\mathrm{F}}\right)$, blend ratio $\left(\mathrm{B}_{\mathrm{R}}\right)$, barrel temperature 
$\left(\mathrm{T}_{\mathrm{Brl}}\right)$, die head temperature $\left(\mathrm{T}_{\mathrm{Die}}\right)$ and screw speed $\left(\mathrm{S}_{\mathrm{S}}\right)$ was done using CCRD and fitting of second degree polynomial equation for representative response surface of data resulted in the development of following model;

Crispness $=94.95-2.15 \times \mathrm{MC}_{\mathrm{F}}+0.69 \mathrm{x}$ $\mathrm{BR}+0.14 \times \mathrm{T}_{\mathrm{brl}}-0.91 \mathrm{~T}_{\mathrm{die}}-0.42 \times \mathrm{SS}-0.01 \times$ $\mathrm{MC}_{\mathrm{F}} \times \mathrm{BR} 0.00 \times \mathrm{MC}_{\mathrm{F}} \times \mathrm{T}_{\mathrm{brl}}+0.00 \times \mathrm{MC}_{\mathrm{F}} \mathrm{x}$ $\mathrm{T}_{\text {die }}+0.01 \times \mathrm{MC}_{\mathrm{F}} \times \mathrm{SS}+0.00 \times \mathrm{BR} \times \mathrm{T}_{\mathrm{brl}}+$ $0.01 \times \mathrm{T}_{\text {die }} \times \mathrm{SS}+0.08 \times \mathrm{MC}_{\mathrm{F}}^{2}+0.00 \times \mathrm{BR}^{2}$ $+6.24 \times \mathrm{T}_{\mathrm{brl}}{ }^{2}+0.00 \times \mathrm{T}_{\mathrm{die}^{2}}{ }^{2}+1.57 \times \mathrm{SS}^{2}$ ...3.1

The $\mathrm{R}^{2}$ had a value of 0.7104 for the model. Brief information is presented in Table 1 .

Regression coefficient and standard error of second order mathematical model are reported the significance of each terms is also reported.

The positive coefficient at linear level indicated that there was increase in response with increase in level of selected parameters and vice versa.

Negative quadratic terms indicate that the maximum value of the response was obtained at the centre point while positive quadratic term gave the minimum response.

The standard deviation, coefficient of variation, mean and predicted residual error sum of square (PRESS) values, coefficient of determination and predicted $\mathrm{R}^{2}$ and adequate precision are given in APPENDIX B (Table 4).

The response surface graphs of the model 3.1 are presented in Fig. 1 to 10. Fig. 1 to 4 show the interactive effect of moisture content of feed with blend ratio, barrel temperature, die head temperature and screw speed respectively on crispness of extrudates.
Fig 5 to 7 show the effect of blend ratio with barrel temperature, die head temperature and screw speed respectively on crispness of extrudates.

Fig. 8 and 9 show the interactive effect of barrel temperature with die head temperature and screw speed respectively on the crispness of extrudates and Fig. 10 shows the response surface of die head temperature and screw speed on crispness of extrudates.

It is seen from Fig. 1, the crispness of extrudates decreases, with decrease in blend ratio of kodo flour powder whereas it increases with increase in moisture content of feed. Also the increase in barrel temperature increases the crispness of extrudates (Fig. 2),

Similarly increase in die head temperature is complimented with increase in crispness of extrudates and with the increase in screw speed crispness of extrudates also improves. When the blend of kodo flour increases it actually increases the fibre content, which may be mainly responsible for reduction in crispness with increase in blend ratio.

Increase in barrel temperature \& die head temperature are mainly the two parameters responsible for proper cooking and thorough heating of moisture present in the mass of melt which when comes out of die creates a better flash off conditions throughout the body of extrudate and thus resulting in a proper porous and rigid structure, which imparts better crispness to the product.

Increase in screw speed is responsible for better mixing of moisture in the body of melt and uniform heating of melt which again contributes in creating a homogenous mass of extrudate by providing ideal flash off condition for super heated vapours to vapourize through the body of extrudate as it comes out of die. 


\section{Hardness}

The multiple regression analysis for hardness of extrudates versus feed moisture content $\left(\mathrm{MC}_{\mathrm{F}}\right)$, blend ratio $\left(\mathrm{B}_{\mathrm{R}}\right)$, barrel temperature $\left(\mathrm{T}_{\mathrm{Br}}\right)$, die head temperature $\left(\mathrm{T}_{\mathrm{Die}}\right)$ and screw speed $\left(\mathrm{S}_{\mathrm{S}}\right)$ was done using CCRD and fitting of second degree polynomial equation for representative response surface of data resulted in the development of following model;

Hardness $=258.24-10.64 \times \mathrm{MC}_{\mathrm{F}}-2.25 \mathrm{x}$ $\mathrm{BR}+2.22 \times \mathrm{T}_{\text {brl }}-2.62 \mathrm{~T}_{\text {die }}-0.94 \times \mathrm{SS}+0.04$ $\mathrm{x} \mathrm{MC}_{\mathrm{F}} \times \mathrm{BR}-0.05 \times \mathrm{MC}_{\mathrm{F}} \times \mathrm{T}_{\mathrm{brl}}+0.06 \mathrm{x}$ $\mathrm{MC}_{\mathrm{F}} \times \mathrm{T}_{\text {die }}+0.02 \times \mathrm{MC}_{\mathrm{F}} \times \mathrm{SS}-0.01 \times \mathrm{BR} \times$ $\mathrm{T}_{\text {brl }}+0.02 \times \mathrm{BR} \times \mathrm{T}_{\text {die }}+0.00 \times \mathrm{BR} \times \mathrm{SS}-$ $0.00 \times \mathrm{T}_{\text {brl }} \times \mathrm{T}_{\text {die }}-0.00 \times \mathrm{T}_{\text {brl }} \times \mathrm{SS}+0.00 \times$ $\mathrm{T}_{\text {die }} \times \mathrm{SS} 0.08 \times \mathrm{MC}_{\mathrm{F}}^{2}+0.00 \times \mathrm{BR}^{2}-4.69 \mathrm{x}$ $\mathrm{T}_{\mathrm{brl}}{ }^{2}+0.00 \times \mathrm{T}_{\mathrm{die}}{ }^{2}+4.33 \times \mathrm{SS}^{2} \quad \ldots 3.2$

The $\mathrm{R}^{2}$ had a value of 0.4257 for the model. The brief information are presented in Table 4. The standard deviation, coefficient of variation, mean and predicted residual error sum of square (PRESS) values, coefficient of determination and predicted $\mathrm{R}^{2}$ and adequate precision are given in APPENDIX B (Table $4)$.

The response surface graphs of the model 3.2 are presented in Fig. 11 to 20 . The Fig. 11 to 14 show the interactive effect of moisture content of feed with blend ratio, barrel temperature, die head temperature and screw speed respectively on hardness of extrudates. Fig 15 to 17 show the effect of blend ratio with barrel temperature, die head temperature and screw speed respectively on hardness of extrudates. Fig. 18 and 19 show the interactive effect of barrel temperature with die head temperature and screw speed respectively on the hardness of extrudates and Fig. 20 shows the response surface of die head temperature and screw speed on hardness of extrudates (Table 1-4).

Table.1 Analysis of variance for crispness of extrudates

\begin{tabular}{|l|l|l|l|l|l|}
\hline Source & $D F$ & SS & MSS & F & P \\
\hline Regression & 20 & 34.08 & 1.70 & 1.34 & $\mathbf{0 . 3 1}$ \\
\hline Residual & 11 & 13.88 & 1.26 & & \\
\hline Total & $\mathbf{3 1}$ & $\mathbf{4 7 . 9 6}$ & $\mathbf{2 . 9 6}$ & & \\
\hline
\end{tabular}

Table.2 Analysis of variance for hardness of extrudates

\begin{tabular}{|l|c|c|c|c|c|}
\hline Source & DF & SS & MSS & F & P \\
\hline Regression & 20 & 65.76 & 3.28 & 0.40 & $\mathbf{0 . 9 6}$ \\
\hline Residual & 11 & 88.69 & 8.06 & & \\
\hline Total & $\mathbf{3 1}$ & $\mathbf{1 5 4 . 4 5}$ & $\mathbf{1 1 . 3 4}$ & & \\
\hline
\end{tabular}

Table.3 Analysis of variance for cutting strength of extrudates

\begin{tabular}{|l|c|c|c|c|c|}
\hline Source & DF & SS & MSS & F & P \\
\hline Regression & 20 & 134.68 & 6.73 & 0.79 & $\mathbf{0 . 6 8}$ \\
\hline Residual & 11 & 92.61 & 8.41 & & \\
\hline Total & $\mathbf{3 1}$ & $\mathbf{2 2 7 . 2 9}$ & $\mathbf{1 5 . 1 4}$ & & \\
\hline
\end{tabular}




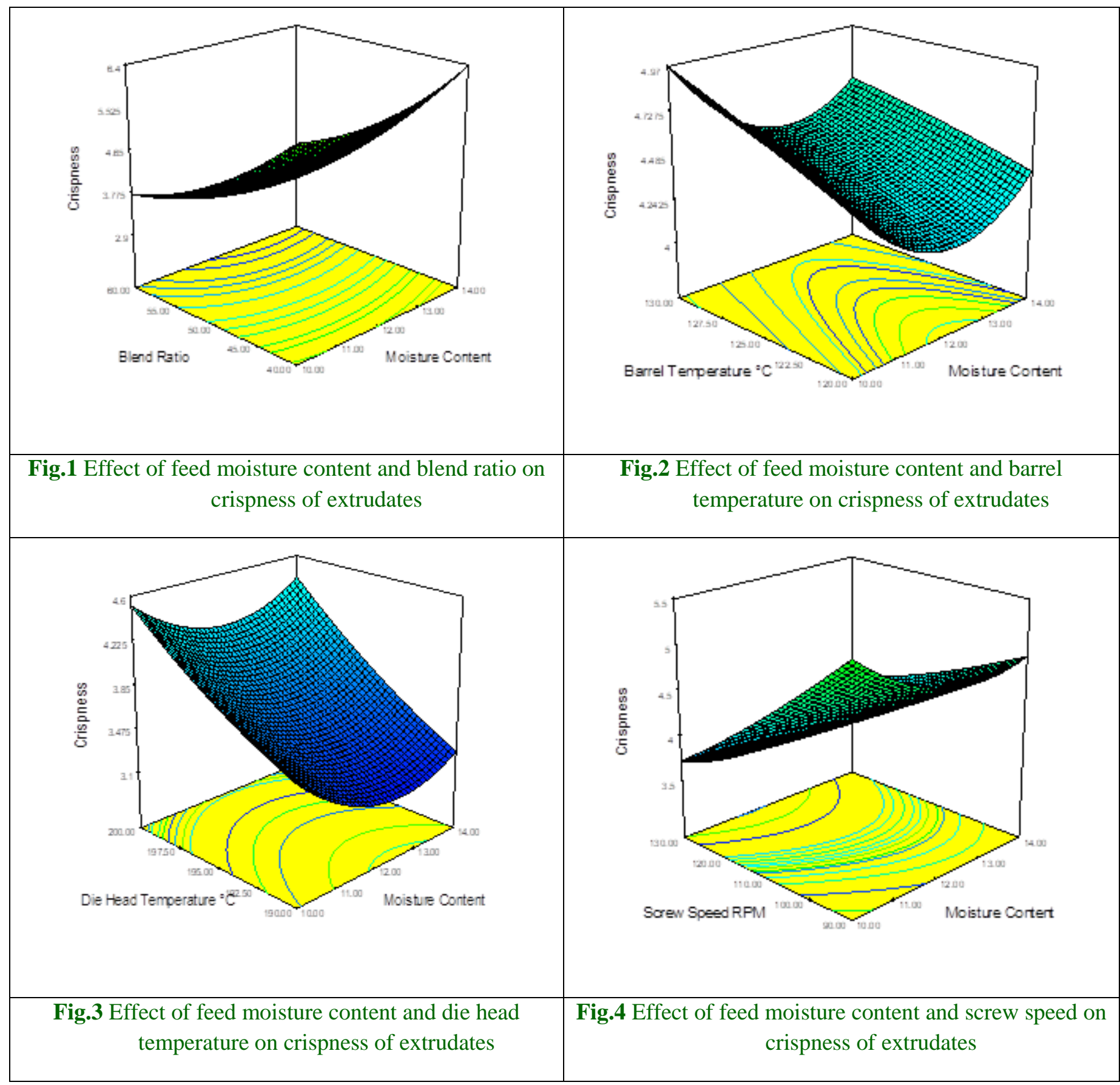




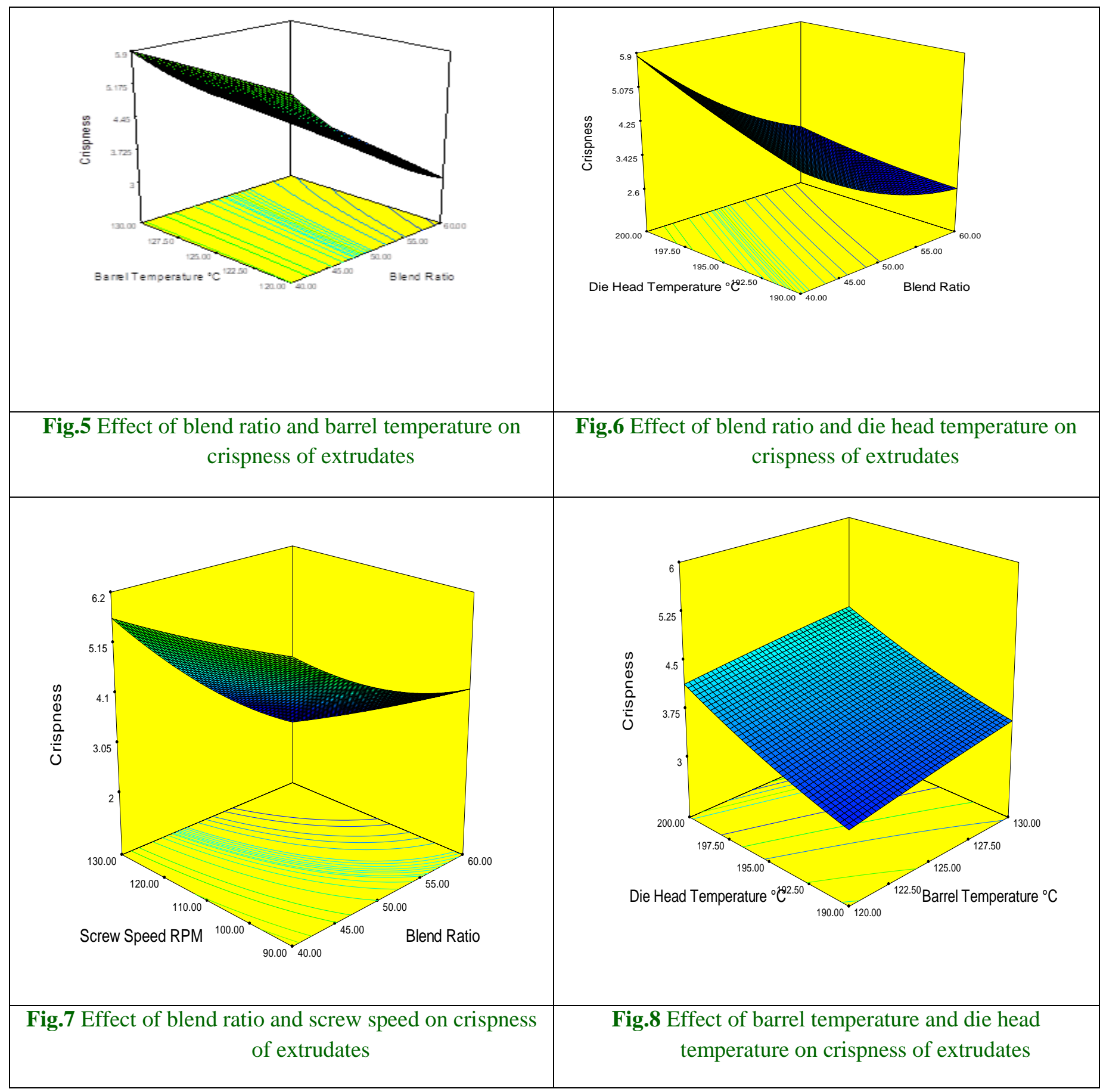



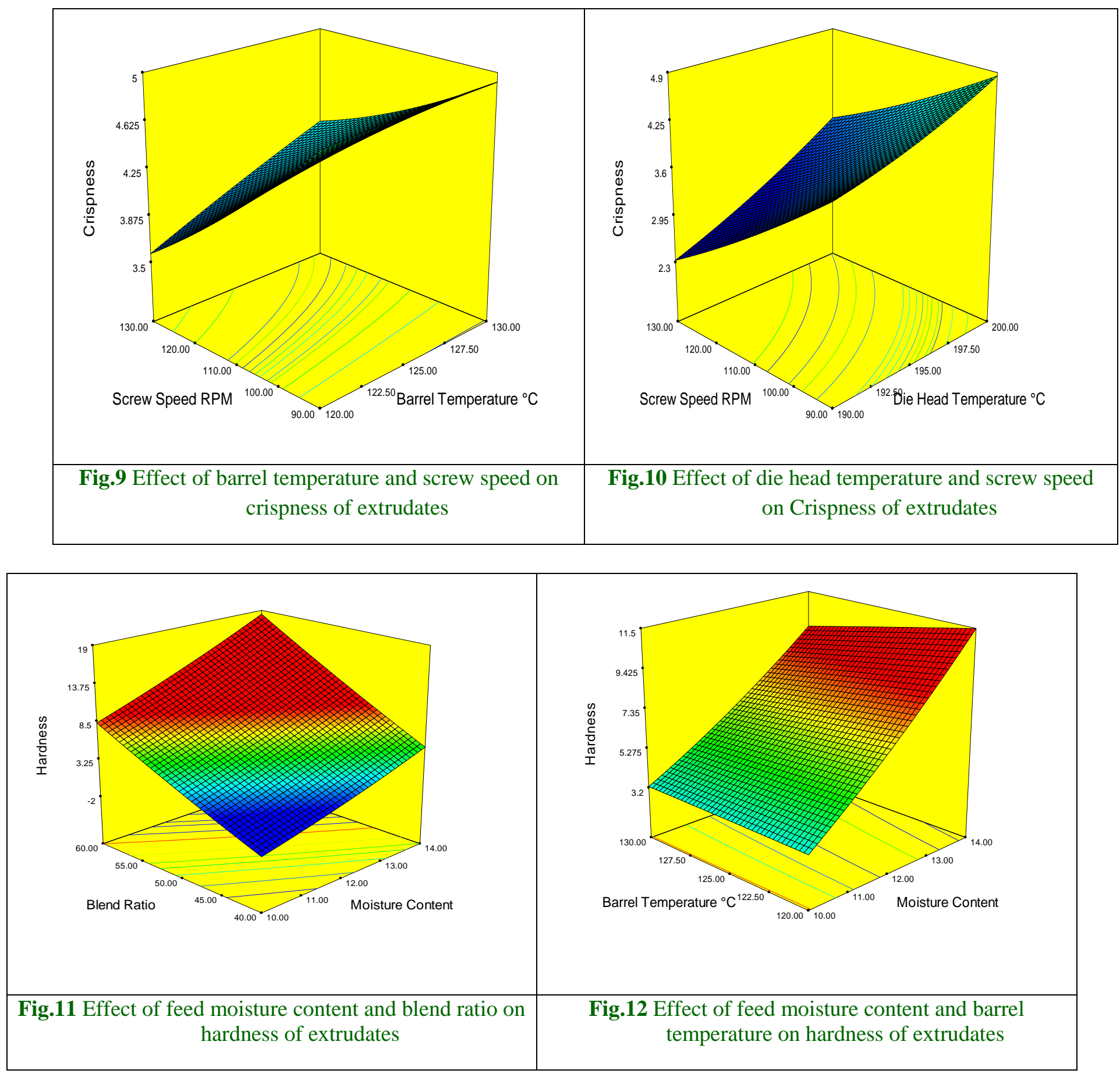


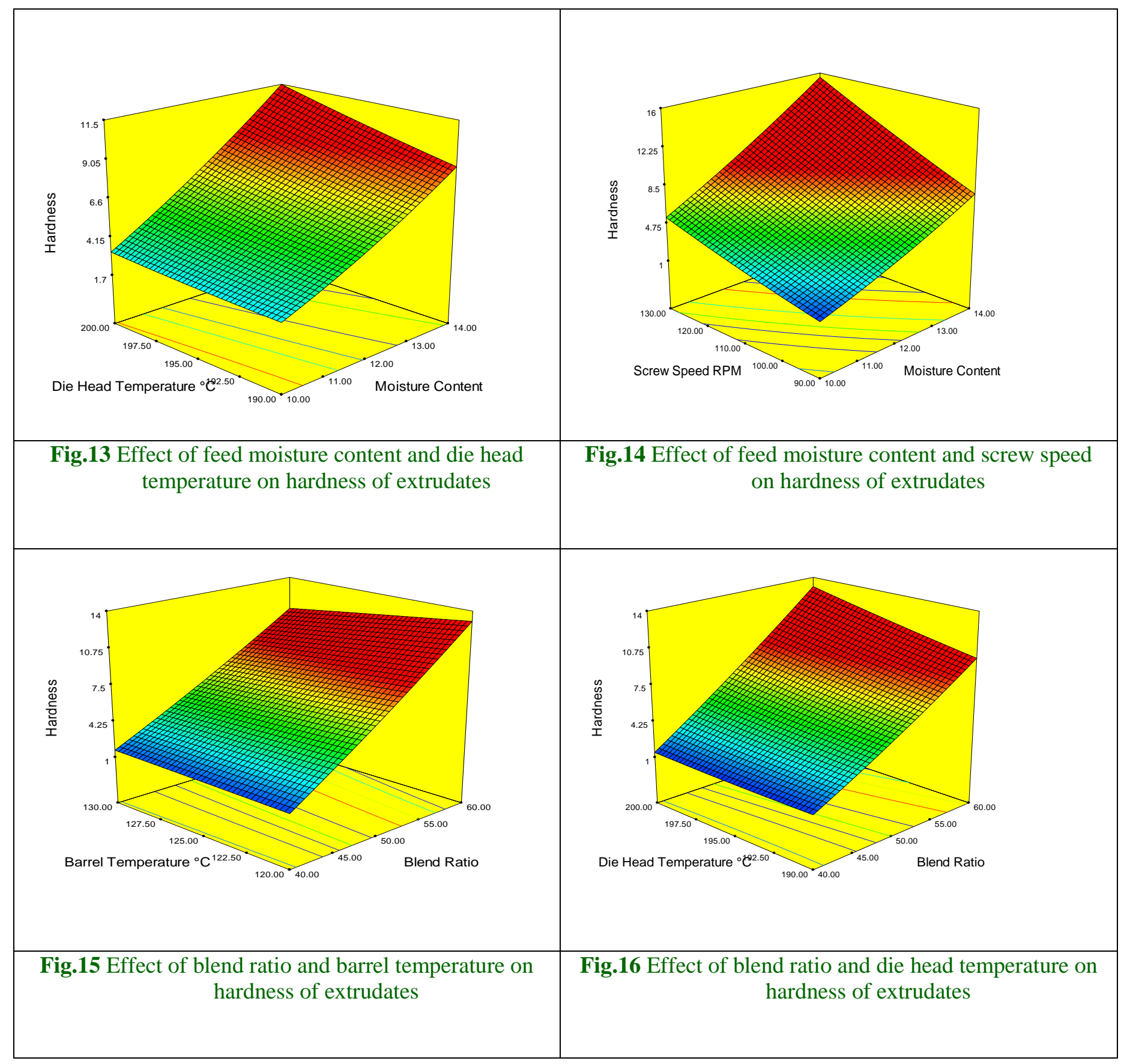




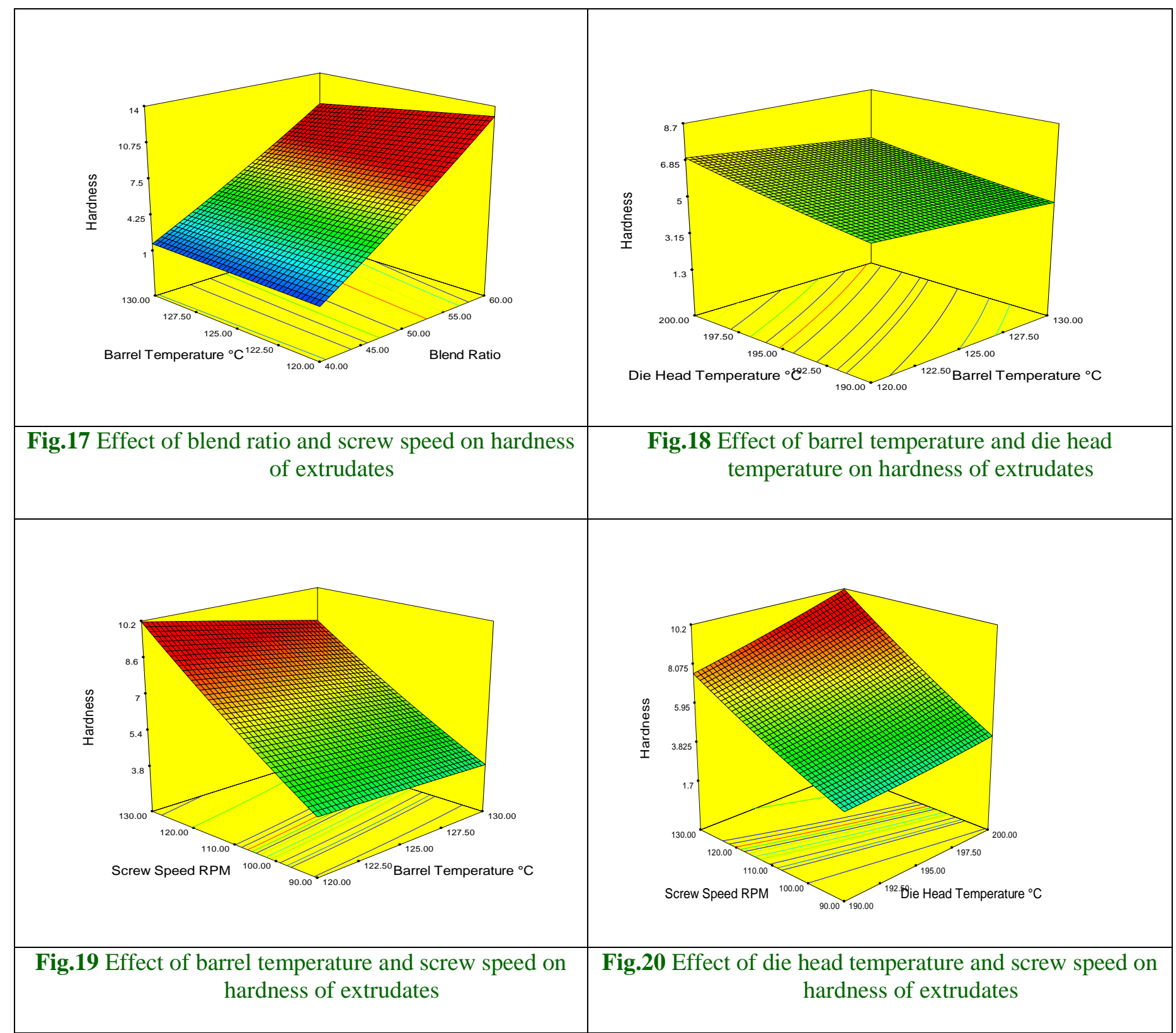




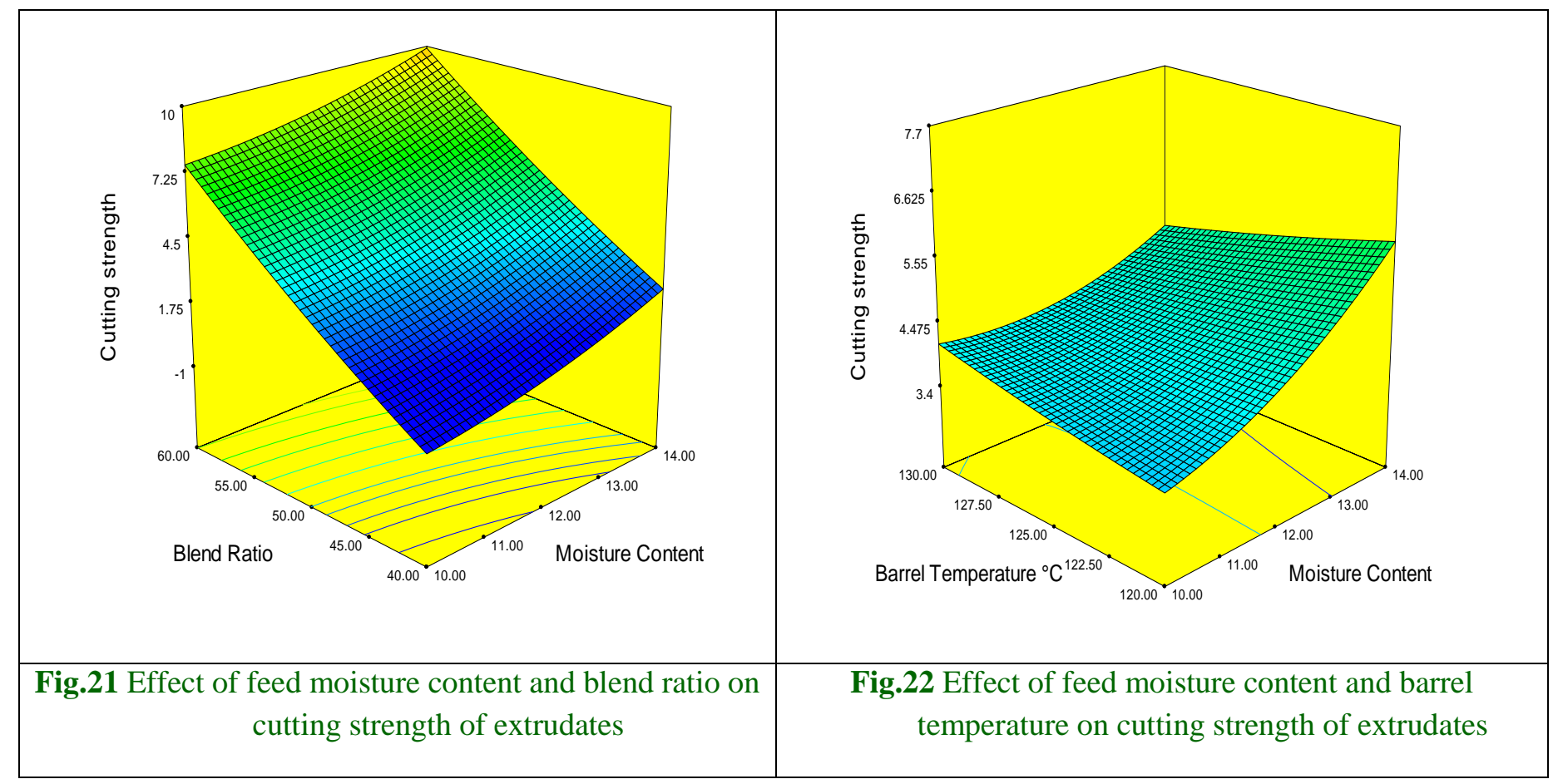

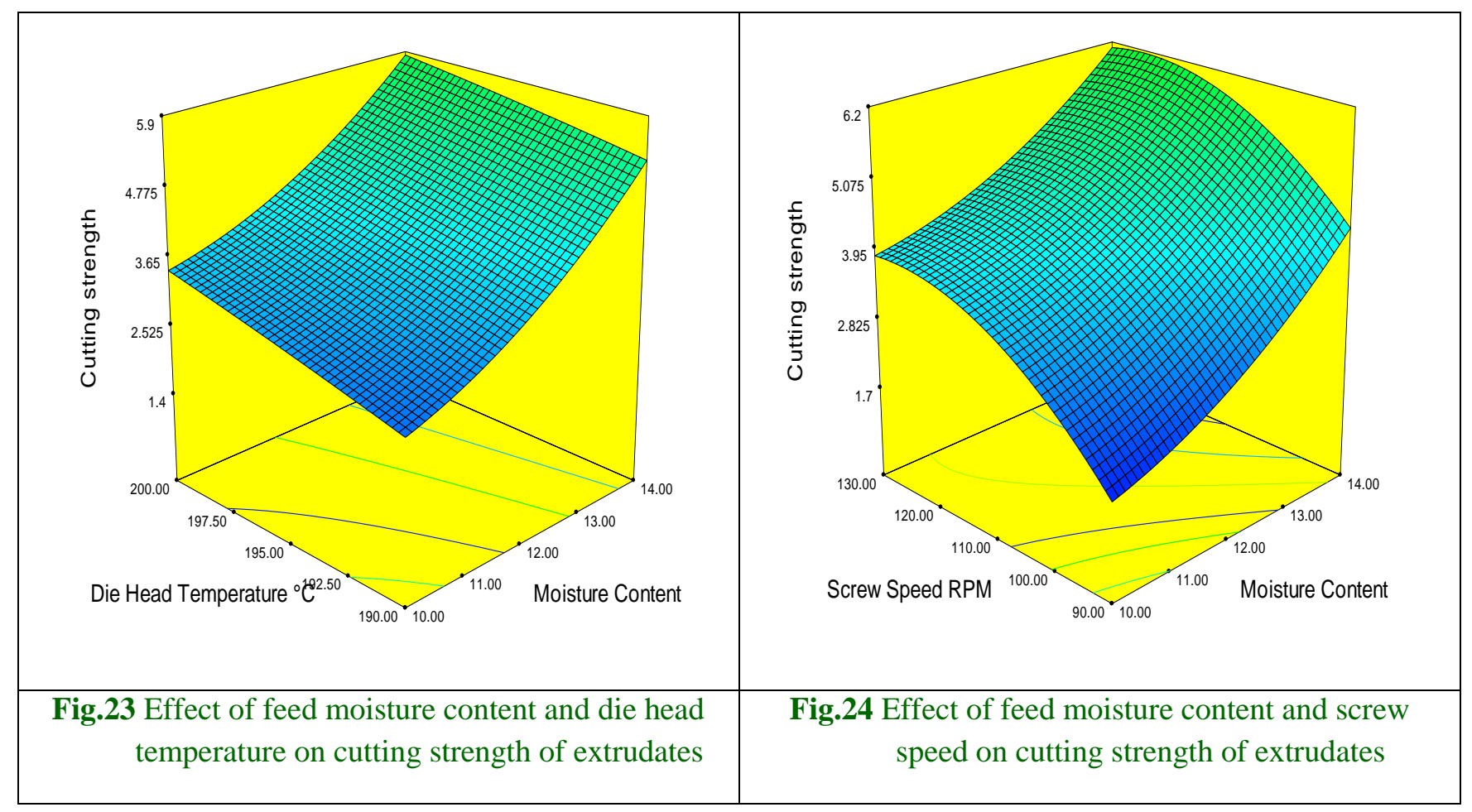




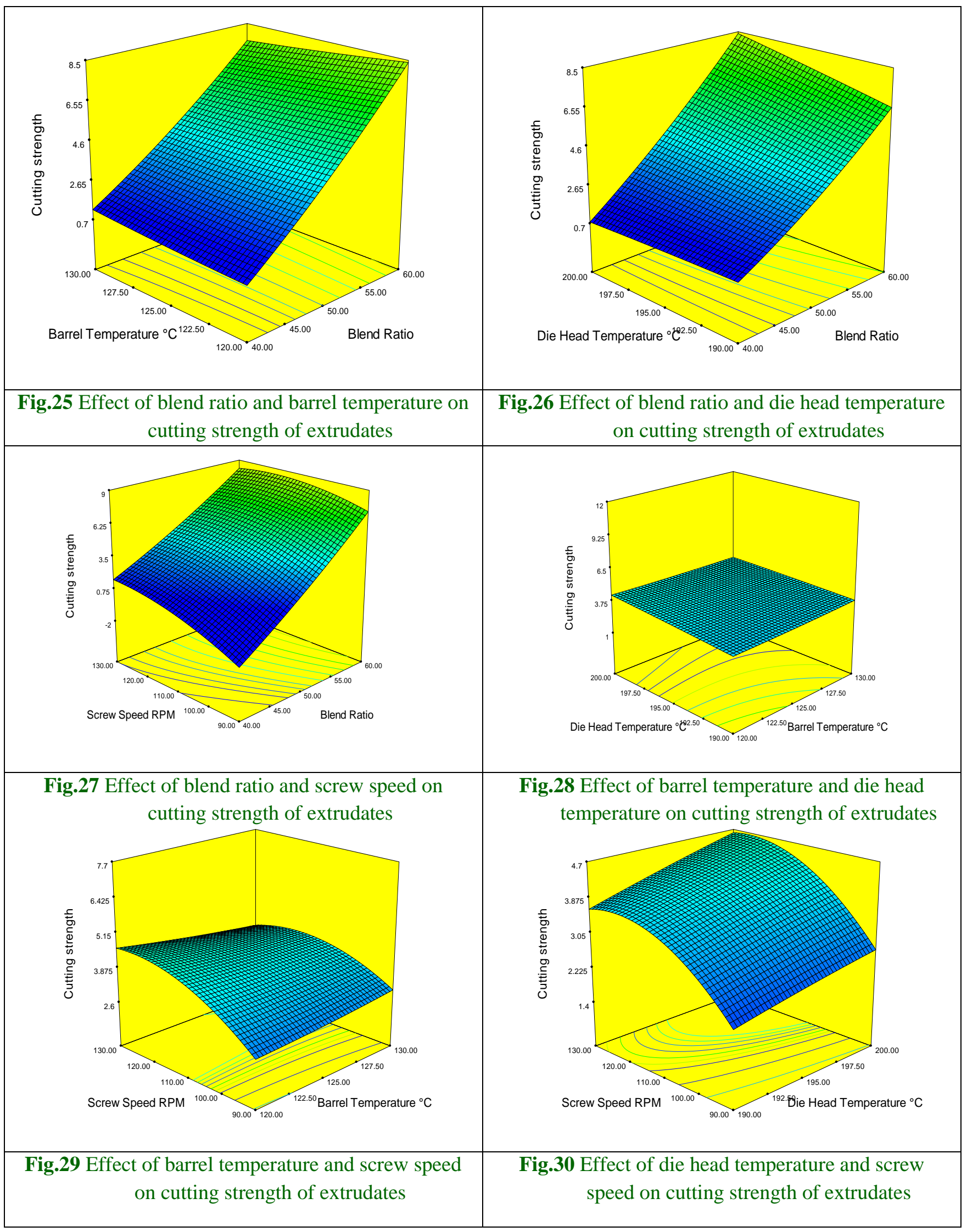


Hardness of extrudate is the resistance offered to breaking when subjected to compressive loading. As seen from Fig. 11 the hardness of extrudates reduces with decrease in blend ratio of kodo flour and has almost no effect with change in barrel temperature and die head temperature and slight increase with increase in screw speed. Hardness of extrudate increases with increase in blend ratio of kodo flour this may be because the dough of kodoflour constitutes a hard mass once it is dried after melting which is mainly due to the characteristics of protein present in kodo flour

As it is seen from Fig. 13 that hardness reduces with increase in die head temperature, which may be mainly due to the changing of fibre content of kodo flour at higher temperature. Increase in screw speed creates a better homogenous mass by better shearing of melt inside the barrel which creates a uniform porous structure of extrudate imparting a soft upper coat to the extrudate.

\section{Cutting strength}

The multiple regression analysis for cutting strength of extrudates versus feed moisture content $\left(\mathrm{MC}_{\mathrm{F}}\right)$, blend ratio $\left(\mathrm{B}_{\mathrm{R}}\right)$, barrel temperature $\left(\mathrm{T}_{\mathrm{Brl}}\right)$, die head temperature $\left(\mathrm{T}_{\text {Die }}\right)$ and screw speed $\left(\mathrm{S}_{\mathrm{S}}\right)$ was done using CCRD and fitting of second degree polynomial equation for representative response surface resulted in the development of following model;

Cutting strength $=\quad-221.7+5.37 \times \mathrm{MC}_{\mathrm{F}}-$ $0.98 \times \mathrm{BR} \times 1.72 \times \mathrm{T}_{\mathrm{brl}}+0.58 \times \mathrm{T}_{\text {die }}+0.67 \times$ $\mathrm{SS}-0.00 \times \mathrm{MC}_{\mathrm{F}} \times \mathrm{BR}-0.04 \times \mathrm{MC}_{\mathrm{F}} \times \mathrm{T}_{\mathrm{brl}}-$ $0.01 \times \mathrm{MC}_{\mathrm{F}} \times \mathrm{T}_{\mathrm{die}}-0.00 \times \mathrm{MC}_{\mathrm{F}} \times \mathrm{SS}-0.01 \times$ BR $\times \mathrm{T}_{\text {brl }}+0.01 \times \mathrm{BR} \times \mathrm{T}_{\text {die }}-0.00 \times \mathrm{BR} \times \mathrm{SS}$ $-0.01 \times \mathrm{T}_{\text {brl }} \times \mathrm{T}_{\text {die }}-0.00 \times \mathrm{T}_{\text {brl }} \times \mathrm{SS}+0.00 \times$ $\mathrm{T}_{\text {die }} \times \mathrm{SS}+0.09 \times \mathrm{MC}_{\mathrm{F}}^{2}+0.00 \times \mathrm{BR}^{2}+0.00$ $\mathrm{x} \mathrm{T}_{\text {brl }}{ }^{2}-0.00 \times \mathrm{T}_{\text {die }}{ }^{2}-0.00 \times \mathrm{SS}^{2} \quad \ldots 3.3$
The $\mathrm{R}^{2}$ had a value of 0.5925 for the model. The brief information are presented in Table 4. The standard deviation, coefficient of variation, mean and predicted residual error sum of square (PRESS) values, coefficient of determination and predicted $\mathrm{R}^{2}$ and adequate precision are given APPENDIX B (Table 4).

The response surface graphs of the model 3.3 are presented in Fig. 21 to 30. Fig. 21 to 24 show the interactive effect of moisture content of feed with blend ratio, barrel temperature, die head temperature and screw speed respectively on cutting strength of extrudates. Fig. 25 to 27 show the effect of blend ratio with barrel temperature, die head temperature and screw speed respectively on cutting strength of extrudates. Fig. 28 and 29 show the interactive effect of barrel temperature with die head temperature and screw speed respectively on the cutting strength of extrudates and Fig. 30 shows the response surface of die head temperature and screw speed on cutting strength of extrudates.

Cutting strength is the resistance offered by extrudates to the shearing force applied by Warner - Bratzler blaze operated through texture analyser. As it is seen from Fig. 21 that increase in blend ratio of kodo flour increases the cutting strength which is mainly because the presence of kodo flour increases the binding strength of solidified melt coming out of die as extrudate. As seen from Figs. 22 and 23 the cutting strength has less change by variation in die head temperature and barrel temperature.

As it can be seen from Fig. 24 the cutting strength increases with increase in screw speed which may be because at higher screw speed greater shear rate is generated which is responsible for uniformly porous, homogenous and soft structure of extrudate thereby increasing the cutting strength. 


\section{References}

Harper J.M. (1981).Extrusion of Foods, Boca Raton, FL, CRC Press, Inc.

Sanchez Acosta, David Riaz, Mian Richter, Ron Rooney, Lloyd W. Waniska ad Ralph D. (2004). White food-type sorghum in direct - expansion extraction applications. Texas A\&M University, http://handle.tamu.edu/1969.1/515

\section{How to cite this article:}

Devendra Kumar, Mohan Singh, Shobha Rani and Varsha Kumari. 2020. Study on Textural Quality of Extrudates Prepared from Different Blends of Sattu and Kodo. Int.J.Curr.Microbiol.App.Sci. 9(06): 3983-3995. doi: https://doi.org/10.20546/ijcmas.2020.906.467

\section{APPENDIX-B}

Table.4 The standard error, mean, coefficient of variation, predicted residual error of sum of squares (PRESS), coefficient of determination, adjusted and Pred R-Squared and adequent precision values for developed models

\begin{tabular}{|c|c|c|c|c|c|c|c|c|}
\hline $\begin{array}{c}\text { Model } \\
\text { No. }\end{array}$ & $\begin{array}{c}\text { St. } \\
\text { deviation }\end{array}$ & Mean & C.V.\% & PRESS & $\mathbf{R}^{\mathbf{2}}$ & Adj. $\mathbf{R}^{2}$ & Pred. $\mathbf{R}^{\mathbf{2}}$ & $\begin{array}{c}\text { Adeq } \\
\text { Precision }\end{array}$ \\
\hline $\mathbf{4 . 1 3}$ & 1.123645 & 4.46875 & 25.1445 & 294.1966 & & 0.184054 & & \\
\hline $\mathbf{4 . 1 4}$ & 2.83964 & 4.284063 & 66.28381 & 1390.967 & 0.425777 & -0.61827 & & \\
\hline $\mathbf{4 . 1 5}$ & $\mathbf{2 . 9 0 1 7 1 2}$ & $\mathbf{4 . 5 7 5 9 6 9}$ & $\mathbf{6 3 . 4 1 1 9 6}$ & $\mathbf{1 5 9 5 . 5 2 5}$ & $\mathbf{0 . 5 9 2 5 3 9}$ & $\mathbf{- 0 . 1 4 8 3}$ & $\mathbf{- 6 . 0 1 9 2 1}$ & $\mathbf{3 . 0 9 0 1 6 6}$ \\
\hline
\end{tabular}

